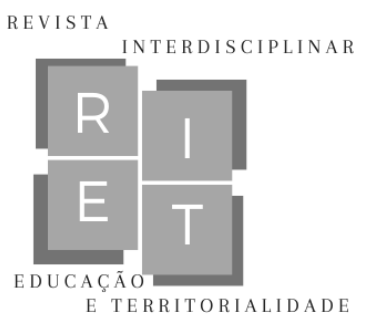

\title{
Experiência de uma professora da educação infantil numa escola do Norte de Minas na Pandemia
}

\author{
Experience of a teacher of early childhood education at a school in North \\ Minas in the Pandemic
}

\author{
Experiencia de una maestra de educación inicial en una escuela del Norte de \\ Minas en la Pandemia
}

\author{
George Fredman Santos Oliveira ${ }^{1}$ \\ Programa de Pós-Graduação em Educação, Universidade Federal de Santa Catarina (UFSC) \\ Florianópolis, Santa Catarina, Brasil \\ E-mail: george.fredman@ufsc.br \\ https://orcid.org/0000-0003-0431-1618 \\ Eliane Vanessa dos Santos Oliveira ${ }^{2}$ \\ Prefeitura Municipal de Mirabela, Secretaria de Educação \\ Mirabela, Minas Gerais, Brasil \\ E-mail: elianvso2018@gmail.com \\ https://orcid.org/0000-0003-2364-3714
}

\begin{abstract}
Resumo: O presente relato de uma professora da educação infantil de uma escola pública municipal de uma pequena cidade do interior do Norte de Minas Gerais objetiva-se um registro do tempo presente como testemunho e compromisso com a tarefa educacional por ocasião da pandemia do Covid-19. Nascido de uma conversação espontânea entre dois irmãos que se ocupam do campo da educação convertida num texto-narrativa, as experiências colhidas e redigidas convergem aspectos da História Oral, História do Tempo Presente, Memória Coletiva e Social. A proximidade dos eventos e a persistência da pandemia enquanto o texto era produzido fazem deste relato-texto uma narrativa no presente em aberto na qual os leitores encontrarão algumas estratégias, práticas, táticas e impressões da profissão docente que procura manter vivo o interesse e a esperança no processo educativo sem denegar as dificuldades, contradições e desafios impostos pelo isolamento social e ensino remoto durante um ano de pandemia pelo Covid-19.
\end{abstract}

Palavras-chave: Educação Infantil, Experiência docente, Covid-19

Abstract: the present account of a kindergarten teacher at a public school in a countryside city of Minas Gerais aims to record the present time as a testimony and commitment to the

\footnotetext{
${ }^{1}$ Graduado em Filosofia pela Pontifícia Universidade Católica de Minas Gerais - PUC/MINAS (2001). Arquivista na Universidade Federal Minas Gerais (UFMG) desde fevereiro de 2019. Integrante do Núcleo de Estudos e Pesquisas Educação e Sociedade Contemporânea - NEPESC e do Núcleo de Pesquisa e Estudos Arquivos Contemporâneos - NUPEAC na Universidade Federal de Santa Catarina.

2 Graduada em Pedagogia pelo Instituto Superior de Educação ISEIB, possui Especialização: Neuropsicopedagogia professora do ensino infantil na Escola Municipal Eva Ruas Guimarães, da prefeitura de Mirabela/MG.
}

RIET-ISSN 2676-0355, Dourados, v. 2, n. 2, p.354 a 367, jan./jun., 2021 


\section{Experiência de uma professora da educação infantil numa escola do norte de minas}

\section{na pandemia}

educational task during the Covid-19 pandemic. Begun as a spontaneous conversation between two brothers who work in the field of education changed into a narrative text, the experiences collected and written converge aspects of Oral History, History of the Present Time, Collective and Social Memory. The proximity of the events and the persistence of the pandemic while the text was being produced make this text-report an open-ended narrative in which readers will find some strategies, practices, tactics and impressions of the teaching profession that seeks to keep interest and hope alive in the educational process without denying the difficulties, contradictions and challenges imposed by social isolation and remote teaching during a year of pandemic by Covid-19.

Keywords: Early childhood education, Teaching experience, Covid19

Resumen: El presente informe de una maestra de jardín de infancia de una escuela pública municipal de un pequeño pueblo del norte de Minas Gerais tiene como objetivo registrar el tiempo presente como testimonio y compromiso con la tarea educativa durante la pandemia del covid-19. Nacida de una conversación espontánea entre dos hermanos que trabajan en el campo de la educación convertida en texto narrativo, las vivencias recogidas y escritas confluyen aspectos de Historia Oral, Historia de la Actualidad, Memoria Colectiva y Social. La proximidad de los hechos y la persistencia de la pandemia mientras se producía el texto hacen de este texto-relato una narrativa abierta en la que los lectores encontrarán algunas estrategias, prácticas, tácticas e impresiones de la profesión docente que busca mantener el interés y Esperanza viva en el proceso educativo sin negar las dificultades, contradicciones y desafíos que impuso el aislamiento social y la enseñanza a distancia durante un año de pandemia por Covid-19.

Palabras clave: Educación infantil, Experiencia docente, Covid-19

Data de recebimento: 30/03/2021

Data de aprovação: 10/06/2021

DOI: $10.30612 /$ riet.v\%vi\%i.14480

\section{Introdução}

O relato a seguir é fruto de uma conversa entre irmãos em que a professora compartilhava comigo um pouco de sua rotina escolar desde a irrupção da pandemia. Estas conversas informais refletiam a preocupação comum de pessoas envolvidas com o campo da educação: de um lado somos testemunhas de um evento que marcará a história, e de outro o compromisso com a tarefa educacional diante das decisões a serem tomadas frente a esta tarefa. Como é ser uma professora numa região predominantemente rural numa escola pública municipal e manter a oferta do ensino administrando as exigências do isolamento social e a utilização de recursos e tecnologias numa realidade com pouca, ou quase nenhuma, familiaridade com tais exigências e recursos? Durante o período pandêmico foi possível tomar conhecimento do que alguns(as) professores(as) e escolas estavam realizando para enfrentar este desafio Brasil a fora, por meio de artigos em periódicos científicos ou mesmo em matérias da mídia ostensiva como a televisão e páginas da rede mundial de

RIET-ISSN 2676-0355, Dourados, v. 2, n. 2, p.354 a 367, jan./jun., 2021 


\section{Experiência de uma professora da educação infantil numa escola do norte de minas na pandemia}

computadores. Consideramos que seria importante dar nossa contribuição relatando a experiência que até então se resumia a uma troca informal, transformando-a num registro textual que alcançasse outras pessoas e lugares que, reconhecendo-se ou não nas situações apresentadas, viessem a tomar conhecimento das dificuldades e estratégias utilizadas num caso concreto de enfrentamento e resistência pelo direito do acesso à educação durante a pandemia de Covid-19.

A existência, a vida nestes tempos convergiram para esse assunto, de certa maneira foram consumidas pela ocorrência da pandemia. A vida local, doméstica que se desenvolvia num fluxo temporal e cultural próprio na pequena cidade, na pequena escola do interior não foi apenas surpreendida por um evento de proporções globais: as relações de proximidade, de afeto, de trocas pessoais se viu bruscamente ameaçada; se é difícil para as pessoas das grandes metrópoles entenderem e aderirem a protocolos rígidos de etiqueta sanitária, tão mais difícil é para as pessoas das cidades interioranas que por maior que seja o contato que possuam com os meios atuais de comunicação, ainda cultivam a sua existência num ritmo diferente: as pessoas se demoram nas casas que visitam, os rituais dos encontros são regados pela partilha do café, das quitandas servidas num prato comum do qual cada pessoa se serve com as próprias mãos sem maiores temores, os domingos da semana são reservados para se receber os filhos e netos que vêm da cidade grande para visitar os familiares que resistem na vida da roça.

A pandemia não havia apenas interrompido a possibilidade do encontro, a pandemia havia mexido com um estilo de vida! O adoecimento do mundo havia se tornado uma preocupação pessoal; falar das preocupações locais, domésticas tornara-se falar das preocupações mundiais, globais. De forma completamente inoportuna, irreflexiva as pessoas se viram participando de uma fatalidade comum, universal. Bizarramente cada pessoa em cada continente poderia se sentir finalmente atingida pela globalização. E o termo a ser usado é este mesmo: atingido, e não incluído (para o caso das afirmações que julgam a pandemia democrática por não fazer distinção entre classes sociais e pessoas, ser vítima de uma doença não pode ser comparado a uma forma de democratização); atingido como por um rompimento de uma barragem de rejeitos, uma enchente, um incêndio, um derramamento de óleo no mar, um golpe de Estado; a despeito dos que negam que estas tragédias sejam tragédias, das implicações políticas, da mobilização humana e humanitária que demanda

RIET-ISSN 2676-0355, Dourados, v. 2, n. 2, p.354 a 367, jan./jun., 2021 


\section{Experiência de uma professora da educação infantil numa escola do norte de minas na pandemia}

para se socorrer os que sobreviverem ao choque, tratar as feridas, juntar o que sobrou, chorar os mortos e reconstruir das ruínas uma vida nova.

A preocupação da professora era a minha, era a preocupação de muitos: como nos proteger, proteger nossos pais, nossos vizinhos, nossos colegas de trabalho; como trabalhar, como manter a renda, como pagar as contas; quanto tempo isto vai durar, quando vamos poder sair de casa e nos reencontrarmos? Esta preocupação é a preocupação mais fundamental e primitiva no ser humano: sobreviver - materialmente e simbolicamente. Morando apenas ela com os nossos pais no interior do Norte de Minas, eu na cidade de Belo Horizonte a uma distância de cerca de 550 km, não me aventurava a encarar a longa viagem num ônibus que poderia estar vedado por causa do ar condicionado, num impulso motivado pela saudade, visitá-los e entrar na casa contaminado. Por esse excesso de zelo a duração da pandemia é a duração do distanciamento aplacado pelas conversas por vídeo-chamada.

O relato a seguir é uma história dentro da história (ou histórias), uma passagem no tempo presente. O relato em si mesmo é despretensioso, no sentido de que não se enquadra em alguma pesquisa cientifica em andamento ou persegue algum enquadramento teóricometodológico a priori; o que não significa que seja desprovido de horizontes no que diz respeito à reflexividade da escrita narrativa no espaço público. Diz do tempo presente (FÁVERO AREND; MACEDO, 2009), mais ainda: do tempo imediato, já que vivido quase em simultaneidade enquanto é narrado: fala-se da pandemia enquanto se vive e morre na pandemia. Diz dos regimes de historicidade do presente fenomenológico (HARTOG, 2013), interpõe o presentismo contra o presentismo da vida acelerada e alienada no excesso informacional para abrir fendas no presente. Diz da narrativa que transita entre a oralidade e a escrita (FERREIRA, 2002). Diz do presente na sua condição de presença (GUMBRECHT, 2009) que se realiza na linguagem. Diz do testemunho (GINZBURG, 2008) e do cotidiano (DE CERTEAU, 2008). Diz da memória e esquecimento (POLLAK, 1989) e da suspensão da oposição entre memória individual e memória coletiva (HALBWACHS, 2013).

O relato a seguir é um exemplar da narrativa do presente como um exercício de encará-lo como história em curso, e embora diga respeito à vivência de um ano cronológico, portanto memória recente, já se apresenta atravessada pelas tensões do esquecimento em virtude dos excessos do presentismo: rápido demais, perto demais, espetacularizado demais... 


\section{Experiência de uma professora da educação infantil numa escola do norte de minas na pandemia}

\section{E o relato começa}

A autora deste relato chama-se Bela ${ }^{3}$, última filha entre três irmãos igualmente com formação de professores; nascida na cidade de Montes Claros, cuja população estimada é composta de 413.487 habitantes (IBGE, 2021) na Região Norte do estado de Minas Gerais, tendo a indústria e o comércio como as atividades econômicas mais importantes. Bela é formada em Pedagogia com especialização em Neuropsicopedagogia e Atendimento Educacional com Ênfase em Educação Inclusiva, está com 34 anos de idade, atualmente reside em Mirabela onde é professora da educação infantil numa escola municipal. Distante cerca de $60 \mathrm{~km}$ de Montes Claros, Mirabela é uma cidade pequena com pouco mais de 13 mil habitantes (IBGE, 2021) e sua economia é baseada na agricultura, pecuária e comércio.

A trajetória escolar de Bela iniciou-se em uma escola pública estadual no ano de 1988 no pré-primário, como era chamado na ocasião, essa escola funcionava numa casa no bairro vizinho ao seu; estudou ali por alguns meses até a escola ser instalada em prédio próprio bem perto de casa, uma esquina abaixo. Nessa escola estudou até concluir a quarta série, sua alfabetização aconteceu dentro dos modelos tradicionais, "confesso que tinha uma certa preguiça em estudar, mas enfim fui alfabetizada, fiquei muito feliz quando comecei a ler" (BELA, 2021), confidencia Bela. Para iniciar a quinta série teve que mudar de escola, pois na época a escola na qual havia iniciado os estudos não ofertava o Ensino Fundamental 2.

Chegando nessa outra escola não se adaptou bem, repetiu a quinta série, ali estudou somente dois anos; no ano seguinte a primeira escola na qual havia estudado começou a matricular para o Ensino Fundamental 2 e devido a essa reformulação, Bela voltou novamente para lá e concluiu todo o restante do Ensino Fundamental e o Ensino Médio.

Terminado o ensino médio começou a procurar emprego; em 2008 foi trabalhar em uma escola de educação infantil particular no bairro vizinho, onde sua irmã já trabalhava e a indicou como monitora do maternal. Era uma escola pequena, funcionava em dois períodos: manhã e tarde; no fim desse mesmo ano a diretora lhe sugeriu fazer o curso de Pedagogia, e que no ano seguinte lhe daria uma turma para trabalhar. "A minha vontade era fazer Educação Física, não Pedagogia!” (BELA, 2021), revela a professora Bela; mas a proposta foi aceita, pois "tive um encantamento e uma grande empolgação na vivência da sala de aula da Educação Infantil" (BELA, 2021).

\footnotetext{
${ }^{3}$ Usamos um nome fictício no momento da submissão, em caso de aprovação será adotado o nome real. 


\section{Experiência de uma professora da educação infantil numa escola do norte de minas na pandemia}

No final de 2008 fez o processo vestibular no Instituto Brasileiro de Educação Ibituruna (ISEIB) e em 2009 começa fazer o curso de Pedagogia e a trabalhar como professora no maternal. Houveram as dificuldades e os desafios tanto na sala de aula com as crianças, como também na sala de aula na condição de estudante. "Mas, enfim, tive muitas aprendizagens e a paixão pela educação infantil só aumentava; teria muito o que aprender com a prática! Errei, acertei, sempre aprendendo, aprimorando e construindo novos conhecimentos" (BELA, 2021). Após três anos se formou e "nunca me arrependi da minha escolha, trabalhei nesta escola até o ano de 2013" (BELA, 2021).

Em outubro de 2013 foi chamada para trabalhar em uma empresa têxtil da cidade; aceitou a proposta e trabalhou até março de 2015, foi uma experiência muito boa, mas a área da educação havia lhe cativado, “trabalhar na educação é um prazer indescritível!" (BELA, 2021).

Em março de 2015 foram abertas inscrições para um concurso público unificado de prefeituras do Norte de Minas Gerais. A professora fez sua inscrição para a prefeitura da cidade de Mirabela/MG porque algum tempo antes os seus pais haviam adquirido uma propriedade rural e decidido que viveriam ali; começou a estudar de forma autônoma, não fez cursinho preparatório, "estudando somente em casa selecionei material, textos, livros; teria que me preparar muito, não podia deixar escapar essa chance!” (BELA, 2021). Bela comenta que todos lhe deram muito apoio, que tinha muita esperança em passar, estava muito concorrido. "Então chegou o dia da prova, mantive a calma e consegui fazer a prova tranquilamente!” (BELA, 2021). Alguns dias depois conferiu o gabarito, viu que havia errado apenas duas questões, "fiquei ansiosa até o dia do resultado. Acompanhei o andamento dos resultados até que veio a notícia que havia conseguido passar em segundo lugar na distribuição de três vagas" (BELA, 2021).

Em fevereiro de 2016 foi escolher os locais das vagas oferecidas, eram vagas em duas escolas e uma creche. Optou pela Escola Municipal Eva Ruas Guimarães localizada em um bairro periférico da cidade de Mirabela/MG onde é ofertada a Educação Infantil, Ensino Fundamental e Educação para Jovens e Adultos (EJA). O seu funcionamento acontece nos turnos da manhã, tarde e noite, com duas turmas de cada série; a escola conta com uma estrutura adequada para atender o desenvolvimento educacional, por exemplo: salas amplas, cantina, sala do professor, quadra esportiva coberta, pátio, sala de recursos multifuncionais

RIET- ISSN 2676-0355, Dourados, v. 2, n. 2, p.354 a 367, jan.jun., 2021 


\section{Experiência de uma professora da educação infantil numa escola do norte de minas na pandemia}

para Atendimento Educacional Especializado, banheiros; nela estão matriculados cerca de 245 crianças, com média de 20 alunos por turma, lá trabalham 45 funcionários.

As crianças não recebem qualquer tipo de bolsas de estudo, a escola é municipal e a Prefeitura proporciona o apoio com reformas (realiza pintura, por exemplo), cuida da limpeza interna e do pátio para as crianças usufruírem dos recreios num local limpo e saudável. A escola fornece diariamente às crianças merenda escolar de ótima qualidade.

A cidade de Mirabela é de pequeno porte com pouco mais de 13.000 mil habitantes (IBGE, 2021), é tranquila para se viver, todos se conhecem; "moro com minha família fora do perímetro urbano, na zona rural e para ir ao trabalho faço o uso do transporte escolar acompanhando as crianças que entram no meu turno e que moram na mesma região" (BELA, 2021).

Quanto à caracterização socioeconômica e cultural da escola: a população é constituída pela classe social baixa e média; a grande maioria das crianças é composta por filhas e filhos de pessoas que trabalham no comércio, de professores, de profissionais da área de saúde, outras que fazem parte da agricultura familiar, e de alguns que saem da cidade de Mirabela/MG e vão trabalhar em Montes Claros/MG, pois é relativamente próxima. Há famílias de baixa renda que vivem somente do Programa do Governo (Bolsa Família). A escola recebe estudantes do perímetro urbano e da zona rural; Bela afirma perceber que muitas famílias são comprometidas com a educação dos filhos; outras não se importam muito. A escola vem se esforçando para levar um ensino de qualidade e confiabilidade pela atuação e competência dos profissionais que nela trabalham.

As crianças da Educação Infantil ao ingressarem na escola se deparam com uma nova realidade, chegam ao meio social mais amplo, o que as vezes acaba gerando muitas inquietações, "percebo que algumas são carentes de afeto precisam de muita atenção, de carinho, de gestos e palavras para que se sintam amadas" (BELA, 2021); segundo Bela as crianças demonstravam capacidade para fazer perguntas e solucionar suas dúvidas por iniciativa própria, algumas crianças apresentavam mais interesse que outras ao realizarem suas atividades, precisando, assim, de apoio; a maioria se concentra conseguindo realizar as atividades com muito capricho. As crianças utilizam materiais variados para realizar as atividades como, giz de cera, lápis de cor, colagem...

$\mathrm{O}$ relacionamento entre as crianças apresenta harmonia, facilitando assim o aprendizado entre elas; durante todas as atividades, as crianças participavam com muito

RIET-ISSN 2676-0355, Dourados, v. 2, n. 2, p.354 a 367, jan./jun., 2021 


\section{Experiência de uma professora da educação infantil numa escola do norte de minas na pandemia}

entusiasmo. No final da aula todas querem brincar, ficando todas impacientes e não permanecendo assentadas, e no intervalo das atividades e no recreio compartilhavam os brinquedos que traziam de casa.

Para Piaget (2002), o desenvolvimento cognitivo das crianças ocorre por meio dos estágios sensório-motor, Bela, citando este autor, relata que convivendo, acompanhando as crianças dia a dia percebe que no ambiente escolar muitas desenvolvem suas habilidades nestes estágios como: sentarem-se de modo correto nas carteiras, conseguem realizar satisfatoriamente os movimentos básicos de andar, correr, pular, mantendo o equilíbrio do corpo e estão sempre dispostas nas brincadeiras. $\mathrm{O}$ ambiente da sala de aula é mantido o tempo todo organizado, quando precisam apontar lápis e jogar papel fora, usam sempre a lixeira no canto da sala. Quando voltam do recreio lavam sempre as mãos. "Sempre tem alguns que gostam de ficar andando pela sala e fora da sala!” (BELA, 2021).

Quanto ao aspecto intelectual, as crianças respondem às perguntas e questionamentos por meio de frases completas, e não somente com uma única palavra. Contam histórias e relatos, usando sempre expressões lógicas e coerentes, às vezes expressões até engraçadas! São assíduas, todas conseguem chegar ao final da etapa da Educação Infantil. Mas infelizmente o ano de 2020 tomou rumos diferentes.

\section{Chegou a pandemia}

As aulas foram interrompidas devido o avanço da Covid-19. "Quando recebemos a notícia de que as aulas seriam suspensas por causa do Novo Coronavírus, estávamos planejando um projeto sobre a água, as crianças estavam empolgadas, pois iríamos fazer uma visita na estação de tratamento de água e esgoto, que foi cancelado" (BELA, 2021).

Com a chegada da pandemia a reação de todos foi de medo, dúvida e expectativa de que logo tudo passaria, muitos acreditavam que não chegaria até a cidade de Mirabela/MG, por se tratar de uma cidade pequena; com o passar do tempo as notícias foram ganhando proporção maior, faleceu uma moradora da cidade, então viram que a doença era bem séria. A cidade ficou bem vazia, foi criado um Comitê de Saúde que intensificou as regras sanitárias, com orientações de lavar as mãos, usar o álcool em gel, proceder a todos os cuidados de higiene. Convivendo com essa dura realidade ainda havia negacionistas que se recusavam em reconhecer o que estava acontecendo! O prefeito juntamente com a equipe de saúde intensificaram todas as medidas por meio de decretos, determinaram a suspensão das

RIET-ISSN 2676-0355, Dourados, v. 2, n. 2, p.354 a 367, jan./jun., 2021 


\section{Experiência de uma professora da educação infantil numa escola do norte de minas na pandemia}

aulas, escolas foram fechadas, crianças orientadas a ficarem em casa, com graves consequências para educação, afetando o calendário e a qualidade do ensino.

Para suprir a alimentação, a prefeitura distribuiu cestas básicas para as famílias, as entregas eram feitas de forma escalonada para evitar aglomeração. Foi realizado um projeto sobre alimentação com receitas variadas e nutritivas utilizando ingredientes comuns e saborosos ao paladar das crianças para, além disso, estimular uma memória afetiva que envolvesse as crianças no preparo junto com a família quando teriam que reproduzir a receita gravada em vídeo e disponibilizada numa plataforma de streaming. Uma ação importante para as crianças serem bem alimentadas, podendo assim ter uma boa saúde para seu processo de desenvolvimento. "Sabemos que a alimentação é essencial para o desenvolvimento da criança e do aprendizado, fora e dentro de sala de aula" (BELA, 2021).

A prática educativa foi realizada com a preparação de atividades impressas e a alimentação. A iniciativa foi mais uma ação para manter a interação entre crianças e os educadores além da aproximação com o ambiente escolar durante o isolamento social, mesmo sendo pela tela de um celular. Para a continuidade das atividades e ações voltadas ao processo de ensino-aprendizagem das crianças, a escola seguiu o planejamento da Secretaria Estadual de Educação (SEE/MG), a escola realizou a implementação do plano, com todas as orientações dos técnicos da secretaria procurando assegurar que todas as crianças tivessem acesso aos conteúdos tentando minimizar os prejuízos ocasionados pela suspensão das aulas presenciais. Vivemos em um contexto marcado por imensos desafios trazidos pela pandemia da Covid-19, então a escola se viu frente à necessidade de continuar com ações mediadas pelo ensino remoto para garantir a continuidade do desenvolvimento e da aprendizagem das crianças.

\section{Dando aula}

Quando sobreveio a recomendação de que todos deveriam ficar em casa para que a propagação da Covid-19 pudesse ser contida, e que as aulas seriam online, Bela se disse preocupada. "Pensei: como fazer os vídeos com o sinal de internet limitado e até mesmo sinal de telefone precário? Mesmo com dificuldade, o sinal de internet chega até minha casa e consigo me ajeitar" (BELA, 2021). Mas além dos vídeos havia também o material impresso que prepararia e as famílias os buscariam na escola, o dia de entrega seria avisado por mensagem ou telefonemas realizados pela secretaria da escola; às vezes a família atendida,

RIET-ISSN 2676-0355, Dourados, v. 2, n. 2, p.354 a 367, jan./jun., 2021 


\section{Experiência de uma professora da educação infantil numa escola do norte de minas na pandemia}

outras, não; o material impresso ficaria dias na escola, alguns pais não iam buscá-los. E escola sempre ligando para saber se as crianças estavam fazendo as atividades.

Com período de quarentena provocada pela pandemia da Covid-19, vieram outros questionamentos que me obrigaram a criar rotinas (JESUS; GERMANO, 2013); uma delas foi o desafio de como trabalhar em casa, veio a pergunta: como farei para engajar as crianças da educação infantil nos estudos em casa? O fato é que a educação infantil apresenta desafios cotidianos para os educadores, por exemplo: estabelecer rotinas com atividades para as quais o planejamento deve atender ao tipo de necessidades dentro da sala de aula (JESUS; GERMANO, 2013), espaço onde as crianças recebem estímulos para desenvolver suas habilidades e tenham a oportunidade de aumentar seu convívio social (DOS ANJOS; FRANCISO, 2021).

Encontramos situações que exigiram um processo de adaptação, um grande desafio nesse período de isolamento. "Minha cabeça ficou cercada de perguntas e questionamentos. Como manter o planejamento fora de sala? Como entregar as atividades as crianças de forma eficiente? Qual ferramenta utilizar para isso? Como lidar com outras dificuldades, como a tecnologia? Como orientar as famílias para realização das atividades propostas pela escola?" (BELA, 2021). Mas foi possível ver que mesmo estando distantes das crianças e da escola não houve impedimento para que planejamento das aulas continuasse sendo seguido, com muitos desafios que precisaram ser superados no dia a dia. E diante do momento conturbado e de adaptação para o ensino à distância foi fundamental manter a execução do planejamento cuidadosamente, sem deixar de cumprir as exigências básicas do currículo escolar, e os campos de experiência como previsto na Base Nacional Comum Curricular (BNCC) de 22 de dezembro de 2017 (BRASIL, 2017).

E no meio disso tudo como estariam as crianças? Segundo a BNCC (BRASIL, 2017) o eixo estruturante da educação infantil são as brincadeiras e interações. E como proporcionar isso às crianças através das telas dos aparelhos digitais? E as crianças que não têm acesso a nenhuma tecnologia? Como seria essa interação? Para proporcionar as vivências descritas nos campos de experiência de maneira envolvente e eficiente utilizando do eixo estruturante da educação infantil só foi possível envolver as crianças nessa trilha do conhecimento de forma muito tímida, este resultado era previsível, pois Bela considerou que muitas famílias perderam seus empregos, não tinham acesso à internet de alta qualidade ou

RIET-ISSN 2676-0355, Dourados, v. 2, n. 2, p.354 a 367, jan./jun., 2021 


\section{Experiência de uma professora da educação infantil numa escola do norte de minas na pandemia}

mesmo não tinham mais do que um ou dois aparelhos digitais com conexão em casa, para estes a realidade ficaria mais difícil!

Muitas famílias acharam esse formato de aula muito ruim, informa Bela, algumas reclamaram dizendo que não estavam sendo pagas para isso (dar aula), e que os professores estavam com preguiça, pediam o retorno das aulas presenciais; outras diziam que não iriam ensinar pois não tinham paciência, ou que a "memória dos telefones estava ficando cheia" (BELA, 2021). Não eram todos que tinham esse pensamento, muitos se empenharam criando rotinas para as crianças, organização ao fazer as atividades, buscavam as atividades no dia e horário combinados, tendo o feedback entre os envolvidos no processo escolar. Ao final do ano letivo foi enviado às famílias um questionário para responderem, ficando evidente que as crianças sentiram muita dificuldade, ficaram estressadas e ansiosas fora do ambiente escolar.

“Trabalhar com as crianças da educação infantil é muito prazeroso" (BELA, 2021), mas requer muita dedicação e aprendizado constante, por isso foi preciso readequar os planos de aulas e as maneiras de fazer com que as atividades e conteúdos chegassem às crianças da melhor maneira possível. "Vivendo este momento difícil, senti a necessidade de adquirir novos conhecimentos e práticas que me ajudassem a implementar as aulas online; então comecei a fazer pós-graduação em neuropsicopedagogia e educação inclusiva" (BELA, 2021).

\section{Um ano depois, ainda na pandemia}

Chegamos em 2021, passamos por um ano difícil. Infelizmente, começamos o ano novo com muito mais desafios, muitas pessoas morreram e estão morrendo, e embora tenhamos as vacinas ainda existe o medo e a insegurança. Visto que o impacto da pandemia permanece ainda este ano, agora é hora de usar a experiência, continuar com o que deu certo e excluir o que não deu, agora novas lições serão aprendidas com essa situação para manternos engajados na educação.

Diante dessa situação foi perceptível que a comunidade escolar não estava preparada para as adversidades, portanto, as escolas precisariam remodelar os trabalhos, os professores precisariam de novos métodos de ensino, as crianças precisariam desenvolver habilidades para que pudessem aprender em casa e as famílias passassem a oferecer mais apoio e participassem ativamente da sua educação.

RIET-ISSN 2676-0355, Dourados, v. 2, n. 2, p.354 a 367, jan./jun., 2021 


\section{Experiência de uma professora da educação infantil numa escola do norte de minas na pandemia}

As dificuldades nos fazem sair da zona de conforto para encontrar soluções e enfrentar os desafios. Com a pandemia ainda instalada, 2021 chegou cobrando um aprendizado para todos da educação, exigindo inovação, criatividade, cultura digital e algumas outras habilidades. Para tanto, o plano de ensino, as decisões sobre ações, estratégias e o currículo ainda deveriam estar consistentes com a BNCC; o acolhimento sócio emocional também é uma responsabilidade da escola, envolvendo o reconhecimento, a compreensão, as emoções, com objetivo de cultivar a empatia e o sentido de responsabilidade na tomada de decisões.

Numa vídeo conferência com o pessoal da gerência municipal de educação e os profissionais da educação, o município e os professores definiram que o ano letivo teria início dia 08 de março, com o parecer de que as aulas continuariam na forma remota; foi cobrado da prefeitura que investisse na formação continuada dos professores oferecendo novas metodologias e o uso de tecnologia; então a equipe gestora da escola reuniu-se com as professoras virtualmente para planejar como seria o início do ano letivo, a partir daí ficou definido que não seriam medidos esforços e nem distâncias para que as crianças tivessem acesso ao ensino. "Novamente a escola adentrou a minha casa, a tecnologia mostrou-se necessária, aprimorando recursos, selecionando as melhores ferramentas, criando atividades para minhas aulas" (BELA, 2021). Ficou evidente neste início que era preciso investir em novas metodologias para ressignificar as práticas pedagógicas.

Criar vínculos socioafetivos, além de pensar em conteúdos faz-se necessário para manter o contato com as crianças mesmo por meio da tela, com a expectativa de que assim os resultados sejam positivos, o apoio da família está sendo fundamental neste início, muitas estão acompanhando melhor os filhos. "As minhas aulas estão sendo feitas por chamada de vídeo do aplicativo WhatsApp, estou feliz pois a nova turminha é bem dinâmica, este ano são onze crianças, todos participam: ligam pra mim, enviam mensagens querendo saber quando vai começar a aula" (BELA, 2021): todas as famílias foram receber o material impresso no dia e horário combinado, estão bem comprometidas com as aulas remotas.

"Adicionei os números das famílias no aplicativo WhatsApp, criando um grupo para a turma, por onde passo áudios e vídeos; o cenário das minhas aulas é um cantinho do quarto, onde gravo vídeos e converso com as crianças" (BELA, 2021). "Por enquanto não conheci as crianças presencialmente" relata a professora Bela, pois os pais tiveram que buscar os materiais impressos sem elas, obedecendo às medidas de segurança. "Procuro nas aulas e

RIET- ISSN 2676-0355, Dourados, v. 2, n. 2, p.354 a 367, jan.jun., 2021 


\section{Experiência de uma professora da educação infantil numa escola do norte de minas na pandemia}

vídeos despertar bastante interesse e que chamem a atenção das crianças, esforçando-me para que não sejam cansativas e chatas" (BELA, 2021); pois nesta forma de ensino corre-se o risco das crianças perderem o interesse.

As aulas devem ter muito movimento e variedade em recursos, como recursos lúdicos, música, histórias e brincadeiras, "elas estão gostando das aulas, e não poderia deixar de tentar fazer algo prazeroso! Estamos interagindo com as aulas ao vivo" (BELA, 2021) (no ano passado não houve aulas ao vivo, era enviado somente os vídeos para assistirem) então está sendo novidade para eles estudar em tempo real, podendo ver todos os colegas e a professora.

\section{O presente em aberto}

O relato não pretende cercear a experiência, que como o presente permanece em aberto, por isto a finalização deste texto é uma suspensão; uma escrita como lampejos da experiência imediata, inconclusa, uma história em curso. O regime de historicidade e a invenção de um cotidiano pandêmico por influxo da fragilidade (ou quase ausência) de anteparos sociais das políticas públicas brasileiras nas áreas da saúde e educação, transporta a narrativa da experiência individual (com os buracos de memória que isto implica) para a experiência coletiva: esta narrativa espera encontrar outras professoras em outros brasis profundos que encaram com esperança a luta educacional. Para este relato não há conclusão, mas um impulso de resistência e de reelaboração do imediato do tempo presente pela "arte do fazer", como diria De Certeau (2008).

\section{Referências}

BRASIL. Base Nacional Comum Curricular. Disponível em http://basenacionalcomum.mec.gov.br/images/BNCC_EI_EF_110518_versaofinal_site.pdf Acesso em 16 jun. 2021

DE CERTEAU, Michel. A invenção do cotidiano: 1. artes de fazer. 15. ed. Petrópolis: Vozes, 2008.

DOS ANJOS, Cleriston Izidro; FRANCISCO, Deise Juliana. Educação infantil e tecnologias digitais: reflexões em tempos de pandemia. Zero-a-Seis, v. 23, n. Especial, p. 125-146, 2021. Disponivel em https://periodicos.ufsc.br/index.php/zeroseis/article/download/79007/45378 Acesso em 16 jun. 2021

FÁVERO AREND, Silvia Maria; MACEDO, Fábio. SOBRE A HISTÓRIA DO TEMPO PRESENTE: Entrevista com o historiador Henry Rousso. Revista Tempo e Argumento, v. 1, n. 1,

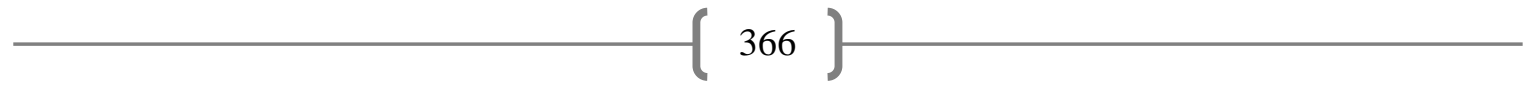

RIET-ISSN 2676-0355, Dourados, v. 2, n. 2, p.354 a 367, jan./jun., 2021 


\section{Experiência de uma professora da educação infantil numa escola do norte de minas}

\section{na pandemia}

p. 201-216, 2009. Disponível em: https://www.revistas.udesc.br/index.php/tempo/article/view/705. Acesso em 30 mar. 2021

FERREIRA, Marieta de Moraes. História, tempo presente e história oral. Topoi (Rio de Janeiro), v. 3, n. 5, p. 314-332, 2002 Disponível em: https://www.scielo.br/pdf/topoi/v3n5/2237-101X-topoi-305-00314.pdf Acesso em 30 mar. 2021

GINZBURG, Jaime. Linguagem e trauma na escrita do testemunho. Revista Conexão Letras, v. 3, n. 3, 2008. Disponível em: https://www.seer.ufrgs.br/conexaoletras/article/viewFile/55604/33808 Acesso em 30 mar. 2021

GUMBRECHT, Hans Ulrich. A presença realizada na linguagem: com atenção especial para a presença do passado. História da Historiografia: International Journal of Theory and History of Historiography, v. 2, n. 3, p. 10-22, 2009. Disponível em: https://www.historiadahistoriografia.com.br/revista/article/download/68/30 Acesso em 30 mar. 2021

HALBWACHS, Maurice. A memória coletiva. (Trad. de Beatriz Sidou) $2^{\mathrm{a}}$ ed. São Paulo: Centauro, 2013

HARTOG, François. Regimes de historicidade: presentismo e experiências do tempo. Belo Horizonte: Autêntica, 2013.

INSTITUTO BRASILEIRO DE ESTATISTICA E GEOGRAFIA. Disponível em: https://www.ibge.gov.br/cidades-e-estados/mg/montes-claros.html Acesso em 16 jun. 2021

JESUS, Degiane Amorim Dermiro de; GERMANO, Jéssica. A importância do planejamento e da rotina na educação infantil. JORNADA DE DIDÁTICA, v. 2, p. 29-40, 2013. Disponível em http://www.uel.br/eventos/jornadadidatica/pages/arquivos/II\%20Jornada\%20de\%20Didatica\%20e \%20I\%20Seminario\%20de\%20Pesquisa\%20do\%20CEMAD\%20-

\%20Docencia\%20na\%20educacao\%20Superior\%20caminhos\%20para\%20uma\%20praxis\%20tran sformadora/A\%20IMPORTANCIA\%20DO\%20PLANEJAMENTO\%20E\%20DA\%20ROTINA\% 20NA\%20EDUCACAO.pdf Acesso em 16 jun. 2021

PIAGET, Jean. Seis estudos de psicologia. $24^{\circ}$ ed. Rio de Janeiro: Florence, 2002

POLLAK, Michael. Memória, esquecimento, silêncio. Revista estudos históricos, v. 2, n. 3, p. 315, 1989. Disponível em:

http://bibliotecadigital.fgv.br/ojs/index.php/reh/article/download/2278/1417\%3B Acesso em 30 mar. 2021

RIET-ISSN 2676-0355, Dourados, v. 2, n. 2, p.354 a 367, jan./jun., 2021 